\title{
An informative set of SSLP markers and genomic profiles in the rat MHC, the $R T 1$ complex
}

Yumie Takagi • Takashi Kuramoto • Birger Voigt •

Toshiko Tsurumi $\cdot$ Satoshi Nakanishi •

Tomoji Mashimo $\cdot$ Norio Masui $\cdot$ Tadao Serikawa

Published online: 2 April 2009

(C) Springer-Verlag 2009

Erratum to: Immunogenetics

$$
\text { DOI 10.1007/s00251-008-0352-9 }
$$

Unfortunately, Figure 1 was published with errors. The correct Figure 1 is given below.

The online version of the original article can be found at http://dx.doi. org/10.1007/s00251-008-0352-9.

Y. Takagi $\cdot$ T. Kuramoto $\cdot$ B. Voigt $\cdot$ T. Tsurumi $\cdot$ S. Nakanishi $\cdot$

T. Mashimo $\cdot$ T. Serikawa $(\bowtie)$

Institute of Laboratory Animals, Graduate School of Medicine,

Kyoto University,

Yoshidakonoe-cho Sakyo-ku,

Kyoto 606-8501, Japan

e-mail: serikawa@anim.med.kyoto-u.ac.jp

Y. Takagi $\cdot$ N. Masui

Japan SLC, Inc.,

Shizuoka, Japan 


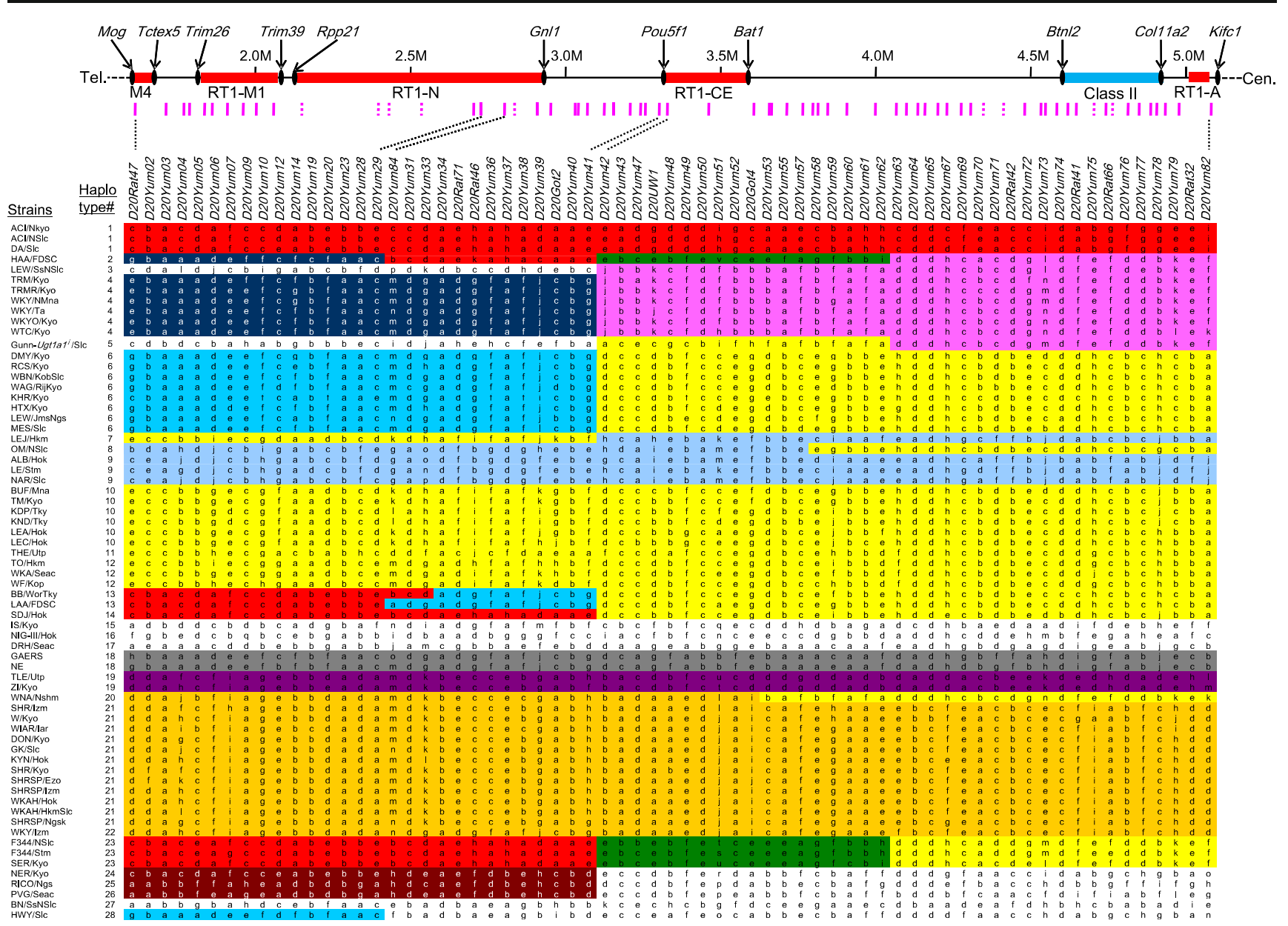

Fig. 1 Distribution of SSLP markers along the RT1 complex gene map and genomic profiles of 67 rat strains. Locations of SSLP markers (pink vertical bars) are indicated along the $R T 1$ complex gene map encompassing from Mog to Kifcl. Markers failing to amplify PCR products are indicated as dotted vertical bars. The gene map includes class I (red) and class II (blue) regions which are defined by their flanking genes (Hurt et al. 2004). SSLP marker profiles of 67 rat strains. These rat strains are sorted based on the assignment on the phylogenic tree. Same haplotype patterns are individually colored. The SSLP marker haplotype of the $R T 1$ complex is roughly divided into three genomic regions: 1; D20Rat47 to D20Yum29, 2; D20Yum84 to D20Yum41, 3; D20Yum42 to D20Yum82 